Chirurgia (2017) 112: 252-258

No. 3, May - June

Copyright@ Celsius

http://dx.doi.org/10.21614/chirurgia.112.3.252

\title{
A Lesser-Known Hepatic Anatomical and Surgical Structure: the Rouviere-Gans Incisura (RGI)
}

\author{
Ionel Cîmpeanu1', Nicoleta Băjenaru², Ana Pușcașu \\ "Carol Davila" University of Medicine and Pharmacy, Bucharest, Romania \\ 'Department of Surgery, "Prof dr. Agrippa Ionescu" Emergency Hospital, Bucharest, Romania \\ ${ }^{3}$ Surgical and Hepatic Transplantation Department, "Sf. Maria” Clinical Hospital, Bucharest, Romania
}

Corresponding author:

Associate Professor lonel Cîmpeanu

"Carol Davila" University of Medicine and Pharmacy, Bucharest, Romania

E-mail: ionel.campeanu@yahoo.com

\section{Rezumat}

O structură anatomo-chirurgicală hepatică mai puțin cunoscută: Incizura Rouviere-Gans (IRG)

Incizura Rouviere-Gans (IRG) reprezintã o structurã anatomochirurgicalã hepaticã relativ frecventã (52\% - 80\% din cazuri), însã puțin cunoscutã în chirurgia hepaticã. Prezența IRG constituie un reper important pentru evitarea leziunilor biliare din colecistectomia laparoscopicã, permite izolarea în $70 \%$ din cazuri a pediculului glissonian (valoean) secțional posterior drept (PGSP) simplificând mult rezectia sectiunii posterioare drepte hepatice sau, a segmentelor sale constitutive (Sg6 şi Sg7). În recoltarea secțiunii posterioare drepte din transplantul hepatic de la donatorul viu, prezența IRG faciliteazã disecția elementelor vasculobiliare din PGSP.

Cuvinte cheie: Incizura Rouviere-Gans (IRG), pedicul glissonian (valoean) sectional posterior drept (PGSP), colecistectomia laparoscopicã, rezecții hepatice reglate, transplantul hepatic de la donatorul viu

\section{Abstract}

Rouviere-Gans incisura (RGI) is a relatively frequent hepatic anatomosurgical structure (it appears in $52 \%-80 \%$ of cases), but it is not wellknown in hepatic surgery. The presence of RGI is an important landmark to avoid biliary lesions during laparoscopic cholecystectomy, since it allows the isolation of the right posterior glissonean pedicle in $70 \%$ of 
cases, therefore simplifying the resection of the posterior right hepatic section or its segments (Sg6 and Sg7). While performing a right posterior hepatic resection for living-donor liver transplantation, the presence of the RGI facilitates the dissection of the vasculo-biliary structures in the right posterior glissonean pedicle.

Key words: Rouviere-Gans incisura (RGI), right posterior glissonean pedicle, laparoscopic cholecystectomy, anatomical liver resections, liver transplant from living donor

\section{Introduction}

Originally described by Rouviere as the groove or fissure of the caudate process ( $\mathrm{CPr}$ ), and by Gans as the dextra incisura, this fissure extends the right extremity of the transverse hepatic groove at the level of the right liver lobe (1-3). This groove, which represents the anterior limit of the $\mathrm{CPr}$ (the "visible" part of the right paracaval territory, formerly Sg9 Couinaud), being parallel to it initially, covers $2-5 \mathrm{~cm}$ in size, with a depth of between $0.5 \mathrm{~cm}$ and $1.5 \mathrm{~cm}$ (rarely $2 \mathrm{~cm}$ ), and overall describes an anterolateral curve with a more slender distal extremity, directed more towards the right hepatic angle and margin (4-7)(Fig. 1). When present, the Rouviere-Gans incisura (RGI) is an important anatomical mark for avoiding biliary lesions during laparoscopic cholecystectomy, for performing hepatic resections at the level of the right liver lobe, and is extremely useful in partial liver transplantation from a live donor (4-12).

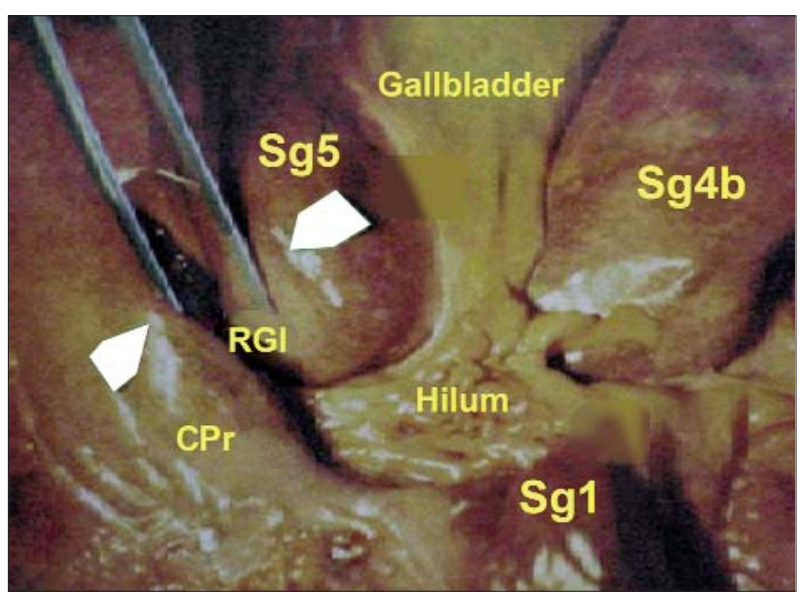

Figure 1. Rouviere-Gans incisura (RGI) (dissection piece) $\mathrm{CPr}$ - caudate process; $\mathrm{Sg}$ - segment 1, 4b, 5)

\section{Material and Methods. Results}

We have sought this incisura throughout 300 cases of laparoscopy or laparotomy performed for various conditions. The presence of RGI was found in $62 \%$ of subjects, with a length between 1 and $3 \mathrm{~cm}$ in $66 \%$ of cases. Using the Zubair-Dahmane classification $(4,8)$, in most situations (70\%), the RGI was open-type along its entire length, and in only $30 \%$ of cases the edges of this incisura were merged along the hilum (fused type), but for no more than 1-2 cm. In nearly half of the "open" RGI cases, a glissonian pedicle could be observed.

\section{Discussions}

Although the presence of RGI is found between $52 \%-82 \%$ of cases $(3-7,13,14)$, in a series of classical or surgical anatomy tratises, this is not even mentioned! (15-17). The anatomical variant in which the RGI is "open type" along its entire length, being in continuity with the hilar axis, is the most commonly encountered (44\%-70\% of situations) and differs from the situation where the two edges -anterior and posterior - of this incisura are fused immediately in juxta-hilar position (fused type) over a distance of $0.5-3 \mathrm{~cm}$ (8). When this tissue bridge is narrow, its sectioning restores the continuity between the right hilum extremity and this groove; if the area of the RGI which is covered has a larger width $(\geq 1.5 \mathrm{~cm})$, cutting this portion of the parenchyma should be performed with care as not to damage the underlying glissonian pedicle (GP).

The surgical importance of RGI has been highlighted relatively recently through papers by Raynaud and Coucoravas, Couinaud, and other authors $(4-8,13,18)$. Initially, Rouviere 
showed that this incision contained "a vascular bundle consisting in the right main branch of the portal vein (PV), of the hepatic artery (HA), and of the biliary tract" (2), and later on Ton That Tung insisted on the isolation by finger fracture of the right glissonian pedicle (RGP) at the right hilum extremity at the level of the dextra incisura (Gans), anterior to the $\mathrm{CPr}$, which is a good anatomical mark for this major portal pedicle (11).

An anatomical-surgical study by Raynaud and Coucoravas noted that in $66 \%-70 \%$ of cases the right sectional glissonian pedicle (RSGP) is found in the proximal portion of this incisura.

Without getting into anatomical details already described elsewhere $(5,19)$, we bring to attention the fact that the main right portal pedicle (MRPP) - responsible for irrigation and biliary drainage of the right hemiliver - is divided in most cases at the right hilum end into two major sectional portal pedicles $(20,21)$, an anterior and a posterior one, which, after entering the liver, become GPs (or valoean) one anterior (ASGP) and the other posterior (PSGP), by recruiting a number of fibrous sleeves or sheaths from the hilar plate (HP), which accompany these GPs up to sinusoidal level (Fig. 2).

A large number of authors consider the MRPP a RGP because it can be surgically isolated "en block", like a genuine GP $(11,22)$. We will however note that, strictly from an anatomical point of view, the MRPP is not a GP because it is not circularly wrapped by a HP-derived conjunctive sleeve, which covers this major portal pedicle as a "shield", but is only cranially covered, and in semi-circular manner.

The ASGP enters the liver vertically and serves the right anterior section (RAS) with segments 5 (Sg5) and 8 (Sg8), while the PSGP bears an almost horizontal trajectory towards the right posterior section (RPS), consisting of Sg6 and Sg7. The two sections (Couinaud sectors) of the right hemiliver (RAS and RPS) are separated from one another by the intersectional right plane (IRP), which is placed in coronal orthostatism and which classically contains the upper right hepatic vein (URHV). The RAS is separated from the left hemiliver through the median hepatic plane (MHP), where the median hepatic vein (MHV) is found $(5,20)$.

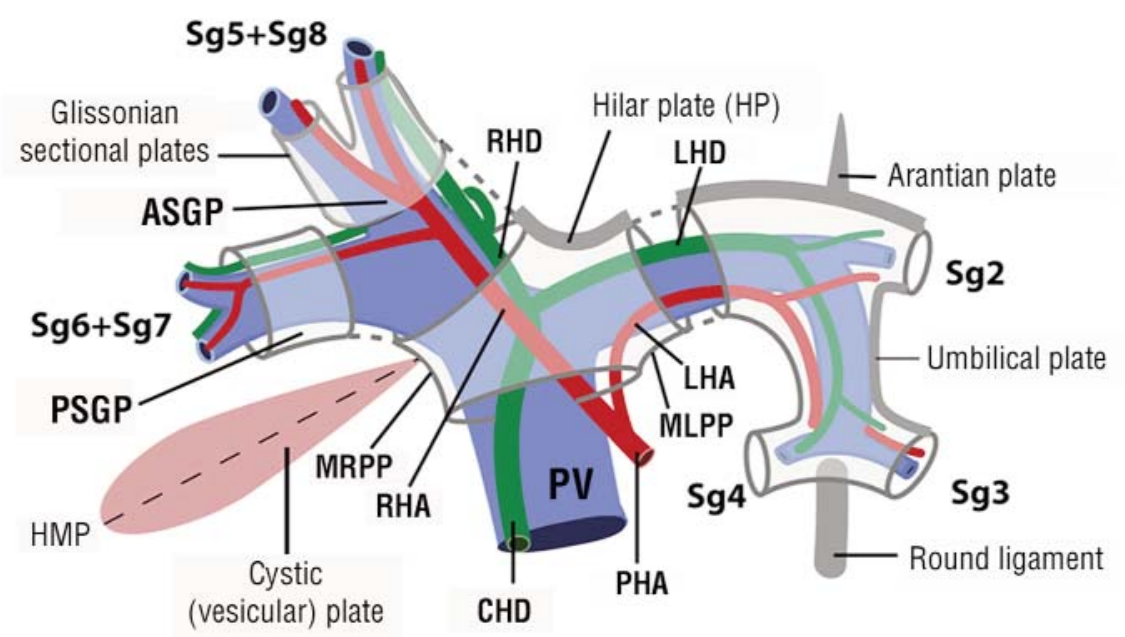

Figure 2. Distribution of the main right and left portal pedicles (MRPP, MLPP), the formation of the two right sectional GPS (ASGP and PSGP) and laying of the three major portal Couinaud plates: the hilar plate (HP), the umbilical plate and the cystic (vesicular)plate. (CHD - common hepatic duct, RHD - right hepatic duct, LHD - left hepatic duct, HMP - hepatic median plane, PHA - proper hepatic artery, RHA - right hepatic artery, LHA - left hepatic artery, PV - portal vein, Sg2-8 - segments 2-8) 
Since according to modal anatomical ("normal") laying the MRPP often has a length of $\leq 1 \mathrm{~cm}$, and the PSGP has an average length of $1 \mathrm{~cm}$, Raynaud and Coucoravas have even described a "point" where the PSGP can be isolated at the start of the RGI, and in practice this is located 2-2.5 cm from the MHP, highlighted at the level of the hepatic hilum - after cholecystectomy - by the attachment of the cystic (vesicular) plate to the anterior edge of the HP $(5,6,7)$ (Fig. 3). In almost half of cases, a GP for Sg6 detaches itself from the anterior edge of the PSGP, and GP detaches for the CPr or for Sg7 $(5,14)$. In practice, dissection in the initial or middle portion of the RGI can highlight, quite frequently (30\%-50\% of cases), a GP of Sg6 instead of PSGP - as a result of a GP of Sg6 detachment from the very origin of PSGP $(22,23)$, or through an early division of this sectional GP, into GP of Sg6 and GP of Sg7. In approximately one third of cases, the surgeon should be advised that in the RaynaudCoucoravas 'point', the PSGP may be replaced by a longer MRPP, by the SAGP origin, by a trifurcation of the MRPP (ASGP + GP of Sg6 + GP of Sg7), or even by the absence of any GP (!), when the GP of Sg6 is located very much towards the anterior side, and that of Sg7 is positioned far behind (5) (Fig. 4).

The presence of RGI has notable implications both in avoiding biliary lesions during laparoscopic cholecystectomy, and in performing anatomical hepatic resections focused mainly on right posterior sectionectomy, or resections of Sg6 and Sg7.

During laparoscopic cholecystectomy, misinterpretation of biliary anatomy is the basis of most biliary lesions which, according to Hugh, are not recognized by the surgeon in three cases out of four (13). According to this author, there is an intraoperative "spatial disorientation" in relation to the anatomical elements of the Calot triangle, similar to the errors encountered by pilots in navigation (airborne, maritime). The strategy to prevent such errors through navigation-derived programs was applied by Hugh in over 2,000 cases of laparoscopic cholecystectomy without any biliary damage. In the case of such a program, an anatomic extrabiliary

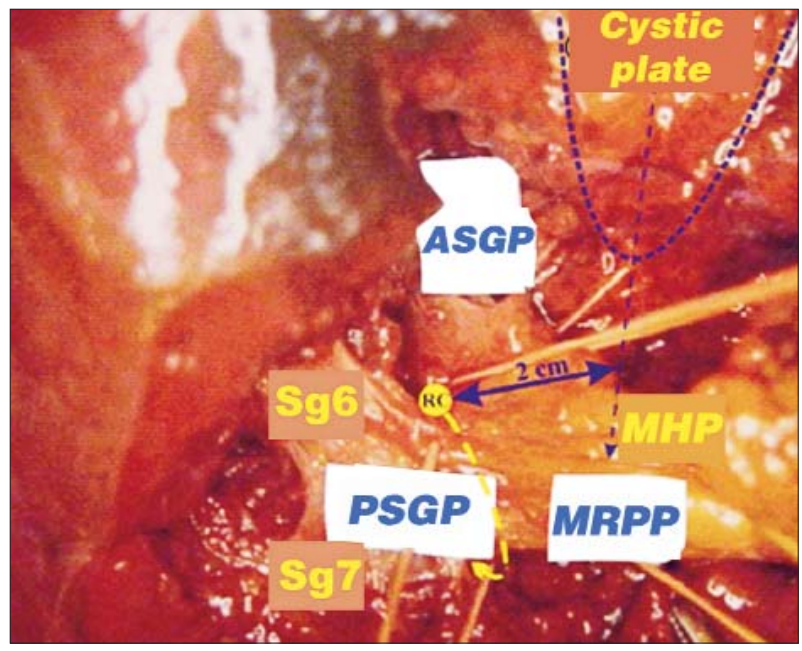

Figure 3. Raynaud-Coucoravas (RC) PSGP isolation "point" (resection piece) (MHP - median hepatic plane)

reference point was the presence of the RGI. Identifying this incisura before beginning the dissection of the Calot triangle is essential in the prevention of biliary lesions. Both the cystic duct and the cystic artery are positioned, without exception, antero-superior to the RGI, while the hepatocholedocus duct (HCD) is located below the RGI plane $(4,8,13,18)$. By the traction exerted by the operator on the gallbladder's neck during the dissection of the Calot triangle, the RGI is positioned at its level, as well as of the cystic duct and of the cystic artery, distal to this level being the HCD. To remind the surgeon of the relationship between the RGI and the gallbladder's hilum, Lockart and Ranger (24) propose the use of the mnemonic term "RANGERS" (Rouvier's At Neck of Gallbladder Eases Recognition of Structures).

With regard to liver resections involving the "opening" of the RIP, these are difficult because this intersectional plane containing the RHV has two characteristics, namely: it is as wide as the width of the right hemiliver and, more importantly, it is extremely variable in its anterior portion $(5,19,22)$. Therefore, an anatomical resection of the RPS (right posterior sectionectomy) or of Sg6 and Sg7 must obtain visibility of the RIP since the beginning of the procedure.

When performing a right posterior sectionectomy or separate resection of the two segmentary components (Sg6 and Sg7), PSGP detection 

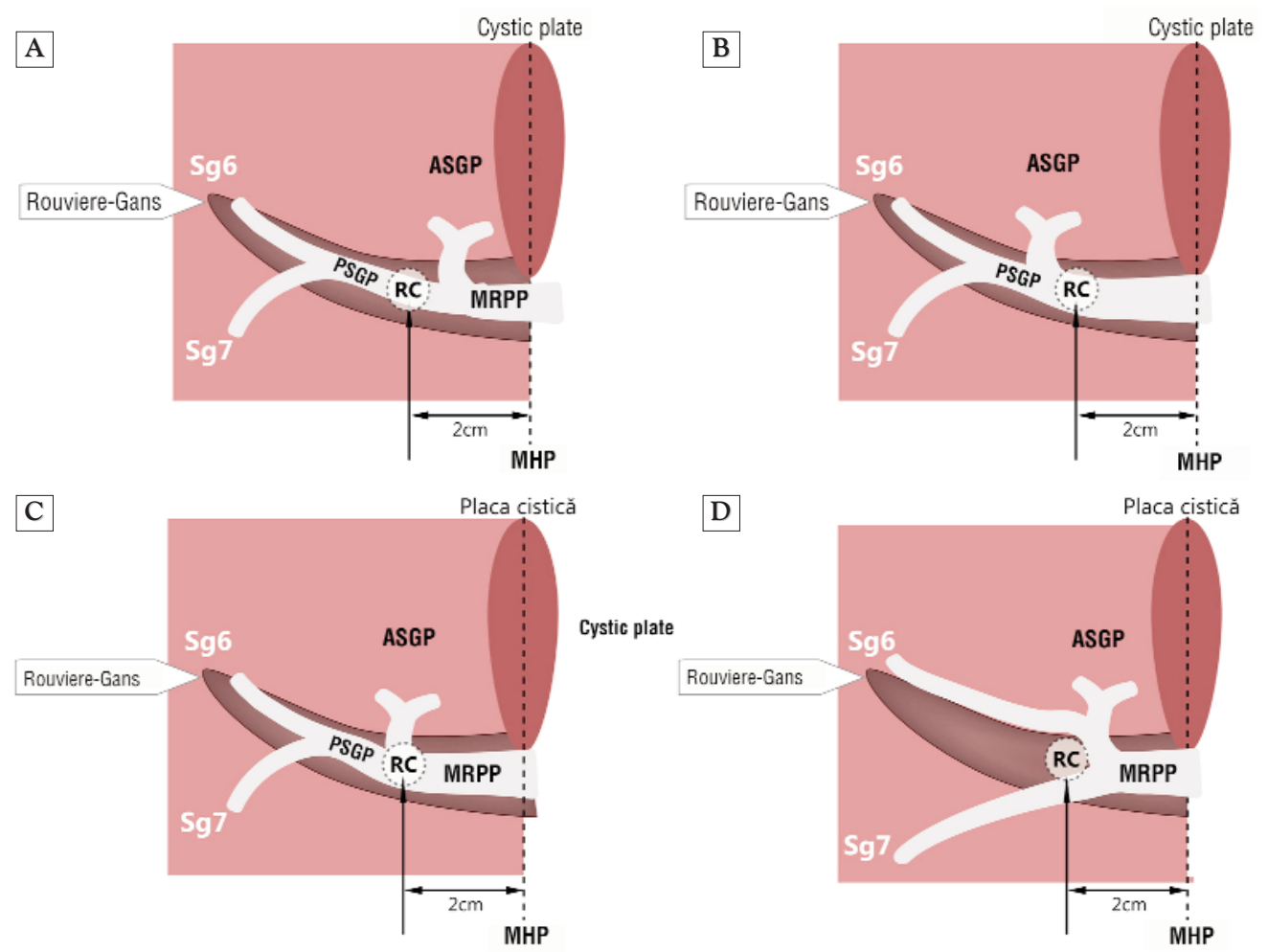

Figure 4. (A) Modal arrangement at RC of PSGP (70\% of cases). Absence of PSGP at RC and its substitution: with a long MRPP (B), with the ASGP (C) or absence of any PG (!) due to the divergent trajectory of the GP of $\mathrm{Sg} 6$ and of $\mathrm{Sg} 7$ (D)

is made - depending on the technique - after the initial isolation of the MRPP and the ASGP and, as a rule, the PSGP is quite profound, not easily visible even after ASGP isolation (22). As we have seen, the presence of RGI simplifies surgery greatly by directly addressing the PSGP at the Raynaud - Coucoravas "point". Isolation of the PSGP should be made "visibly", in order not to damage a GP of the CPr or $\mathrm{Sg} 7$ originating from the posterior edge of this sectional pedicle; the deep surface of the PSGP may be near the right inferior hepatic vein (RIHV, Makuuchi vein), the surgical "star" of short (accessory) veins, which may be unwantedly intercepted during this dissection (Fig. 5). Once having isolated the PSGP, the latter is clamped and the RIP is made visible and brought forward (Fig. 6).

When dissection of the RGI reveals a GP of Sg6, it can be isolated centripetally up to the level of the PSGP, and in the absence thereof, to the division point of the MRPP. In any case, an ultrasound exam of the inferior hepatic surface, as well as isolated GP clamping, detects local anatomical variants and highlights in terms of ischemia and duration the territory served by the isolated GP.

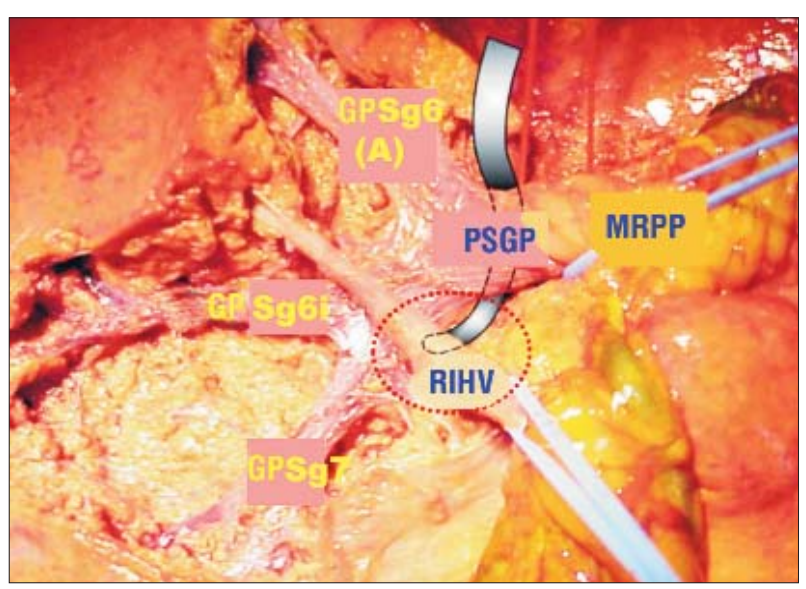

Figure 5. Relationship between RIHV and the deep surface of the PSGP and the risk of injury to this vein, angular GP Sg6 (A), GP 6i (intermediate). 


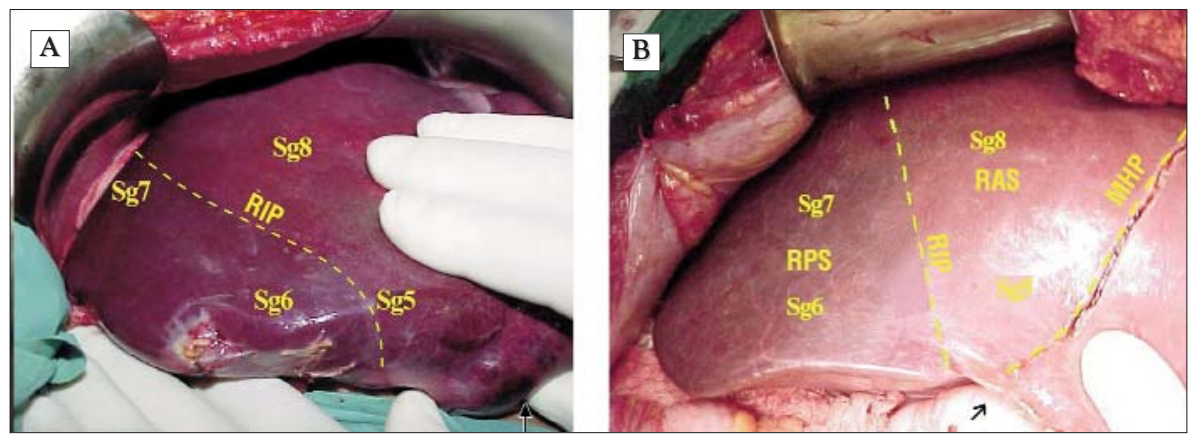

Figure 6. Clamping the PSGP allows visibility of the RIP in a modal position (A) or previously moved towards the right edge of the cystic plate (B). In this last anatomical aspect, Sg6 occupies the entire anterior margin of the right hemiliver, and $\mathrm{Sg} 5$ is rather small $\rightarrow$ the gallbladder

The presence of the RGI also facilitates the isolation of the ASGP, required in the case of a right anterior sectionectomy (Sg5 + Sg8), of a central bisectionectomy (mezzo-hepatectomy, $\mathrm{Sg} 4$ + Sg5 + Sg8 resection) (10), or of a left trisectionectomy. Thus, the dihedral angle formed by the plane passing through the anterior margin of the RGI and the vertical plane, immediately to the right of the cystic plate in the juxta-hilar area, constitutes the right limit in the isolation of the ASGP by limited incisions (mini incisions), as according to the Machado et al. technique. (9).

In situations where the RGI is absent (30\%$35 \%$ of cases), the direct approach of the PSGP or afferent segmental GPs can be obtained by surgically extending to the right over a $2-3 \mathrm{~cm}$ distance the hilar axis, i.e. by a right hilar debridement (RHD), practically an "artificial" RGI, a manoeuver described by Couinaud as early as 1957 (5). Through this incision, either the PSGP or frequently, a GP of Sg6 (Fig. 7)
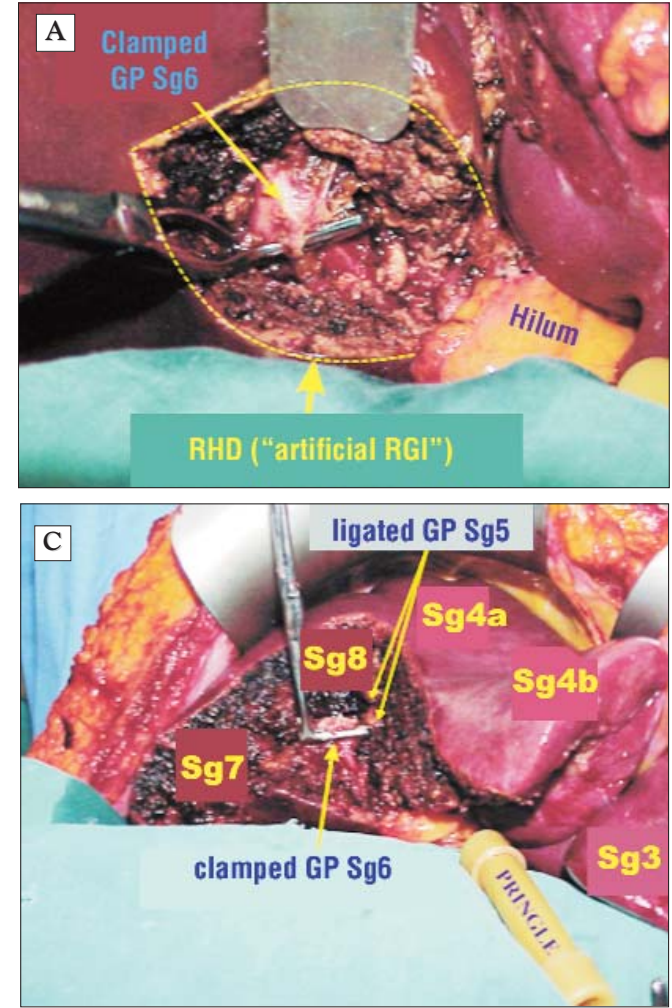

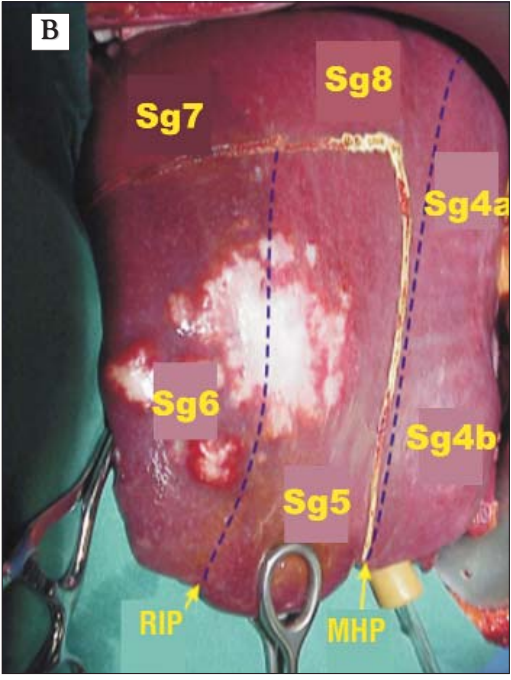

Figure 7. Right hilar debridement (RHD) or "artificial" RGI with GP isolation of Sg6 and its clamping (A), highlighting the anterior section of the right intersectional plane (RIP), positioning of the tumour compared to this plane (B) and performing an anatomical resection of $\mathrm{Sg} 6$ and Sg5 (GPs of Sg5are intercepted in the parenchyma) (C) 
can be approached; if the GP of Sg6 is isolated, its clamping will reveal the ischemic hepatic territory, the anterior portion of the RIP, as well as the positioning of the tumoral mass in relation to this plane.

Finally, we need to show that the RGI facilitates the dissection of the constituent elements of the portal triad forming the PSGP, in situations where the RPS is harvested in the case of transplantation from a living donor (12).

\section{Conclusions}

- The Rouviere-Gans incisura (RGI) is a relatively constant anatomical structure and present in $52 \%-82 \%$ of cases.

- When present, the RGI is an important extrabiliary anatomical reference mark in avoiding biliary lesions during laparoscopic cholecystectomy. The beginning of Calot triangle dissection should be performed after RGI identification because both the cystic duct and the cystic artery are positioned antero-superior to this incision, and the hepatocholedocus duct (HCD) is located below the RGI plane.

- The presence of RGI allows isolation in $70 \%$ of cases of the PSGP in the Raynaud - Coucoravas "point", thus simplifying right posterior sectionectomy and segmental resections constitutive of this section (Sg6 and Sg7).

- RGI identification is also a useful reference point in isolating the ASGP and performing other types of anatomical resections; also, when harvesting the right posterior section during live donor transplantation, this incision facilitates the dissection of the anatomical elements that make up the PSGP.

\section{References}

1. Rouviere H. Anatomie Humaine. Delmas A. TOME II TRONC Descriptive et topographique. Dixieme Edition Revisee (Deuxieme tirage). Editura Masson et Cie. p 377.

2. Rouviere H. Sur la Configuration et la Signification du Sillon du Processus Caude. Bulletins et Memoires de la Societe Anatomique de Paris 1924, 94:355-8.

3. Gans H. Introduction to Hepatic Surgery. Elsevier Publishing Company; 1955.

4. Dahmane R, Morjane A, Starc A. Anatomy and surgical relevance of Rouviere's sulcus. Scientific World Journal. 2013;2013:254287. doi: 10.1155/2013/254287. eCollection 2013.

5. Couinaud C. Surgical anatomy of the liver revisited. 1988.

6. Raynaud B, Coucoravas GO, Giuly JA, Basis to improve several hepatectomy techniques involving the surgical anatomy of incisura dextra of Gans. Surg Gynecol Obstet. 1991;172(6):490-2.

7. Raynaud B, Coucouravas G, Amoros JP, Giuly J, Direct clamping of the right lateral pedicle of Glisson's capsule. Anatomicosurgical study in a case of hepatocaval injury. J Chir (Paris). 1982;119(8-9): 533-41. French

8. Zubair M, Habib L, Memon F, Mirza MR, Khan MA, Quraishy MS. Rouviere's Sulcus: a Guide to Safe Dissection in Laparoscopic Cholecystectomy. Pakistan Journal of Surgery. 2009;25:119-121.

9. Machado MAC, Herman P, Machado MCC. A standardized technique for right segmental liver resections. Arch Surg. 2003; 138(8):918-20.

10. Wu CC, Ho WL, Chen JT, Tang CS, Yeh DC, Liu TJ, et al. Mesohepatectomy for centrally located hepatocellular carcinoma: an appraisal of a rare procedure. J Am Coll Surg. 1999;188(5):508-15.

11. Tung TT. Les Resections Majeures et Mineures du Foie. Editura Masson; 1979.

12. Hwang S, Lee SG, Lee YJ, Park KM, Kim KH, Ahn CS, et al. Donor selection for procurement of right posterior segment graft in living donor liver transplantation. Liver Transpl. 2004;10(9):1150-5.

13. Hugh TB. New strategies to prevent laparoscopic bile duct injury -surgeons can learn from pilots. Surgery. 2002;132(5):826-35.

14. Surjan RCT, Makdissi FF, Machado MAC. Anatomical basis for the intrahepatic glissonian approach during hepatectomies. Arq Bras Cir Dig. 2015;28(2):128-31. English, Portuguese

15. Hollinshead WH. Anatomy for Surgeons Vol 2. - The Thorax, Abdomen and Pelvis. Editura Harper and Row Publishers; 1971.

16. Anson BJ, McVay CB. Surgical Anatomy 5th Edition. Editura WB Saunders Company; 1971.

17. Warwick R, Williams PL. Gray's Anatomy 35th Edition. Editura Longman; 1973.

18. Nagral S. Anatomy Relevant to Cholecystecomy. J Min Access Surg 2005;84:176-181.

19. Cîmpeanu I. Rezectiile hepatice extraglissoniene în chirurgia ficatului Vol. 2. Popescu I. Coordonator. Bucuresti: Editura Universitara Carol Davila; 2004. p 665-741.

20. Strasberg SM. Liver Terminology and Anatomy. În: Lau WY. ed. Hepatocellular carcionoma. Editura World Scientific Publishing Co. Pte. Ltd.; 2008. p 25-50.

21. Popescu I, Cîmpeanu I. Anatomia Chirurgicală a Ficatului si Rezectiile Hepatice - Terminologia Brisbane 2000. Chirurgia 2000, 104: 7-10;

22. Launois B, Jamieson GG. Modern Operative Techniques in Liver Surgery. Editura Churchill Livingstone; 1993.

23. Ryu M, Cho A. Editors. New Liver Anatomy: Portal Segmentation and the Drainage Vein. Editura Springer; 2009.

24. Lockhart S, Singh-Ranger G. Rouviere's sulcus-Aspects of incorporating this valuable sign for laparoscopic cholecystectomy. Asian J Surg. 2016 Sep 16. pii: S1015-9584(16)30123-3. doi: 10.1016/.asjsur.2016.07.012. [Epub ahead of print] 